Check for updates

Cite this: Nanoscale Adv., 2019, 1, 1847

\title{
Bio-inspired temporal regulation of ion-transport in nanochannels $\uparrow$
}

\author{
K. P. Sonu, (D) a Sushmitha Vinikumar, (D) a Shikha Dhiman, (D) b Subi J. George (D)*b \\ and Muthusamy Eswaramoorthy (D) *a
}

Temporal regulation of mass transport across the membrane is a vital feature of biological systems. Such regulatory mechanisms rely on complex biochemical reaction networks, often operating far from equilibrium. Herein, we demonstrate biochemical reaction mediated temporal regulation of mass transport in nanochannels of mesoporous silica sphere. The rationally designed nanochannels with $\mathrm{pH}$ responsive electrostatic gating are fabricated through a hetero-functionalization approach utilizing propylamine and carboxylic acid moieties. At basic $\mathrm{pH}$, cationic small molecules can diffuse into the nanochannels which release back to the solution at acidic $\mathrm{pH}$. The transient ion transport is temporally controlled using a base as fuel along with esterase enzyme as the mediator. The slow enzymatic hydrolysis of a dormant deactivator (ethyl acetate) determines the lifetime of transient encapsulated state, which can be programmed easily by modulating the enzymatic activity of esterase. This system represents a unique approach to create autonomous artificial cellular models.

Received 24th December 2018

Accepted 11th March 2019

DOI: $10.1039 / \mathrm{c} 8 \mathrm{na00414e}$

rsc.li/nanoscale-advances temporally programmed functions similar to natural systems are very few. ${ }^{19-22}$ Prins and co-workers designed systems showing transient signalling and transient catalysis. ${ }^{23-25}$ Using a transient pH switch, Walther and co-workers have exemplified the applications in out-of-equilibrium photonics. ${ }^{26}$ Very recently Ulijn and co-workers elegantly designed enzyme responsive chromophores for transient electronics. ${ }^{27}$

Amongst a plethora of autonomous functions, selective transport of molecules in and out of the cellular compartments is a vital feature of biological systems. In order to achieve this selective transport, cell employs various sophisticated membrane channel proteins. ${ }^{28}$ There have been significant efforts to mimic such selective transport of molecules across the cell membrane in artificial nanochannels. ${ }^{29-33}$ However, all such artificial systems that demonstrated selective transport of molecules often operate in a passive manner and lack autonomous behaviour, unlike their natural counterparts. ${ }^{34-45}$ To alleviate this scenario, herein we report a unique temporal regulation of ion transport in synthetic nanochannels using a bio-inspired, chemical fuel-driven strategy. In order to show this concept of 'transient ion transport', we have used pH responsive, heterogeneously functionalized nanochannels of mesoporous silica particles as a model system (Scheme 1). Moreover, we obtain a control over the slow release of encapsulated cationic molecule which can be used for controlled payload/drug release.

aterials and Catalysis Laboratory, Chemistry and Physics of Material School of Advanced Materials (SAMat), Jawaharlal Nehru Centre for Advanced Scientific Research, Jakkur P.O., Bangalore 560064, India. E-mail: eswar@jncasr.ac.in ${ }^{b}$ Supramolecular Chemistry Laboratory, New Chemistry Unit, School of Advanced Materials (SAMat), Jawaharlal Nehru Centre for Advanced Scientific Research, JakkurP.O., Bangalore 560064, India.E-mail: george@jncasr.ac.in; subijg@gmail.com $\uparrow$ Electronic supplementary information (ESI) available. See DOI: 10.1039/c8na00414e

\section{Results and discussion}

For a transient ion transport, the first condition is to synthesize charge-switchable nanochannels that can undergo charge 


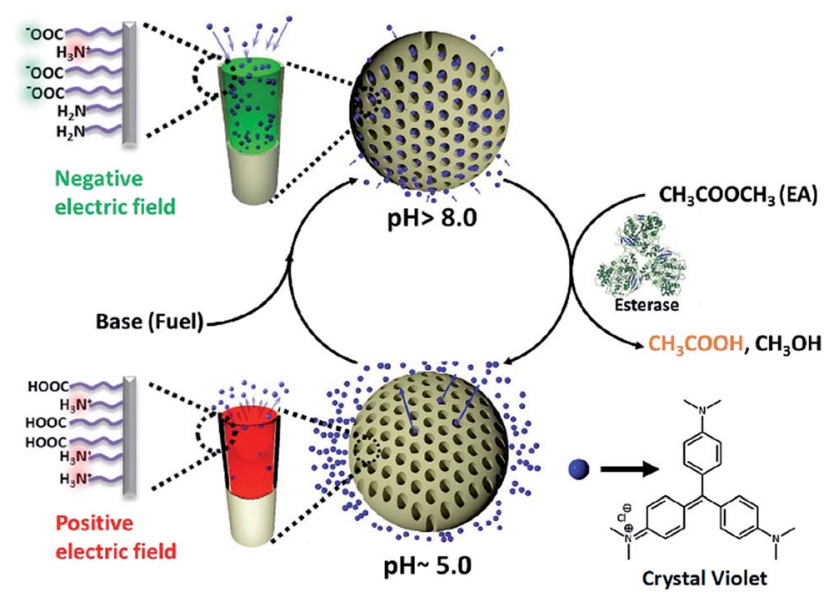

Scheme 1 Bio-inspired enzyme regulated temporal regulation of ion transport in nanochannels: the $\mathrm{pH}$ responsive charge reversal in mesoporous silica nanochannels (MCM-Z) is integrated with a nonlinear $\mathrm{pH}$ modulating enzymatic reaction - ethyl acetate (dormant deactivator, DD) hydrolysis by esterase. At the equilibrium state $(\mathrm{pH} \sim$ 5.0), the transport of the cationic dye (crystal violet, $\mathrm{CV}^{+}$) is blocked due to electrostatic repulsion. Injection of chemical fuel (base) along with dormant deactivator (ethyl acetate) reverses the surface charge of the compartments, which leads to the uptake of the $\mathrm{CV}^{+}$. At the basic $\mathrm{pH}$, the enzymatic hydrolysis (catalysed by esterase present in the system) of ethyl acetate (DD) brings the $\mathrm{pH}$ down to acidic $\mathrm{pH}$ that subsequently release the dye from the nanochannels. The transient ion transport can be temporally programmed by variation of concentration of the chemical components.

reversal on the addition of an external chemical fuel (activation). The second requirement is to have a chemical reagent that can revert the changes in a temporal manner (deactivation). Importantly, the steps should work in tandem, with the rate of activation higher than the rate of deactivation. As the chemical fuel consumed, rate of deactivation becomes higher and the system comes to equilibrium. For this, we have heterogeneously functionalized nanochannels of mesoporous silica particles with $\mathrm{pH}$ responsive amine and carboxylic acid functional groups (Scheme 1). Mesoporous silica spheres (MCM-41, hereafter referred as MCM) (Fig. S1 and S2 $\dagger$ ) were synthesized following a well-known sol-gel procedure and the surface was covalently modified with (3-aminopropyl)triethoxysilane to obtain MCM-N with amine functionalized surface ${ }^{46,47}$ A portion of amine groups was then reacted with succinic anhydride to form $\mathbf{M C M}-\mathbf{Z}$ with zwitterionic nature having carboxyl and amine groups on the nanochannel surface (Fig. S1 $\dagger$ ). The XRD patterns of MCM, MCM-N and MCM$\mathbf{Z}$ exhibited a small angle peak (at around $2 \theta=2.5$ degree) suggesting that the hexagonal mesostructure was retained during functionalization (Fig. S3 $\dagger$ ). Retention of mesoporosity of nanochannels was further confirmed via transmission electron microscopy (Fig. 1a). Thermogravimetric analysis (TGA) suggested propylamine functionalization in MCM-N was around $c a$. $2.0 \mathrm{mmol} \mathrm{g}^{-1}$ (Fig. S4 $\dagger$ ). The carboxylic acid groups (-COOH) in MCM-Z was determined to be around $c a .1 .1 \mathrm{mmol} \mathrm{g}^{-1}$ using TGA and ninhydrin test (Fig. S5 $\dagger$ ), which suggest that approximately $56 \%$ of amine groups were covalently connected (via amide linkage) to carboxylic acid groups in MCM-Z. (a)
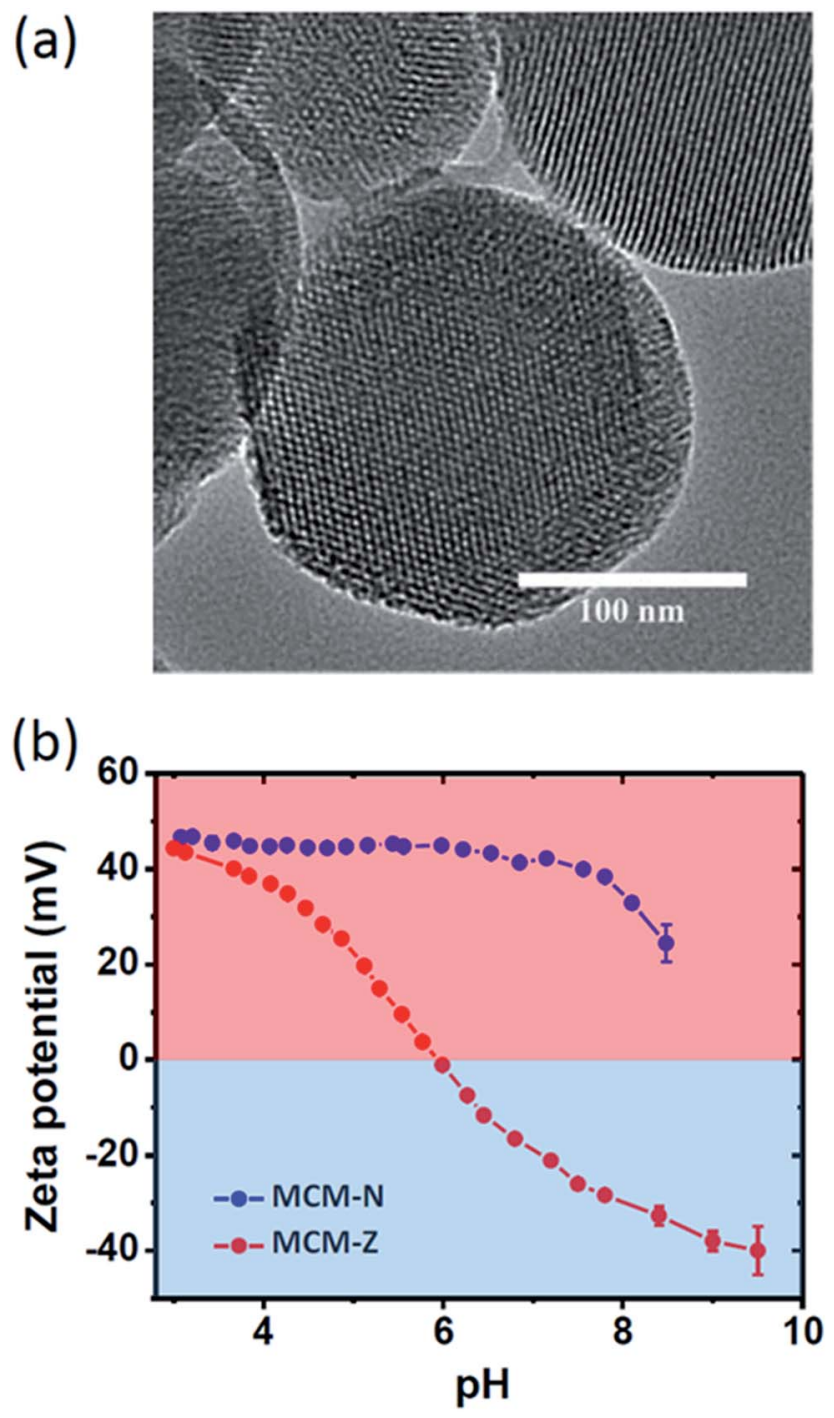

Fig. 1 (a) TEM image of MCM-Z. (b) pH dependent zeta potential for MCM-N and MCM-Z.

Nitrogen adsorption-desorption analyses were carried out at $77 \mathrm{~K}$ to evaluate the progress of functionalization inside the nanochannels (Fig. S6a $\dagger$ ). The Barrett-Joyner-Halenda (BJH) pore size distributions showed a gradual reduction in average pore size from $c a .2 .9 \mathrm{~nm}$ for MCM to $2.5 \mathrm{~nm}$ for MCM-N which further decreased to $2.2 \mathrm{~nm}$ for $\mathbf{M C M}-\mathbf{Z}$ suggesting progress of functionalization inside the nanochannels (Fig. S6b $†$ ). Further, the number of propylamine groups on MCM-N was calculated to be 1.25 molecules per $\mathrm{nm}^{2}$ area from $\mathrm{N}_{2}$ sorption studies and TGA (see ESI $\dagger$ text for details). Similarly, in the case of MCM-Z, the number of carboxylic acid groups present was around 0.71 molecule per $\mathrm{nm}^{2}$.

To monitor the surface charge of these biomimetic nanochannels, we employed zeta potential measurements. The variation of zeta potential with $\mathrm{pH}$ for both MCM-N and MCM$\mathbf{Z}$ were shown in Fig. 1 b. As expected, propylamine functionalized MCM (MCM-N) showed a zeta potential of $c a .+46 \pm$ $0.5 \mathrm{mV}$ at $\mathrm{pH} 3$ that reduced to $+24 \pm 2 \mathrm{mV}$ at $\mathrm{pH} 8.5$. In the 
case of MCM-N, no charge reversal occurred on going from low pH to high pH (Fig. 1b, S7 $\dagger$ ). On the other hand MCM-Z (that have both amine groups and carboxylic acid groups on the surface) showed a clear charge reversal with respect to $\mathrm{pH}$. At pH 3, MCM-Z was positively charged with a zeta potential of ca. $+44 \pm 0.5 \mathrm{mV}$ associated with the protonation of free amines in MCM-Z. The surface charge became zero at around pH 6 (isoelectric point) and a further increase in pH caused charge reversal from positive to negative with a zeta potential of ca. $-32 \pm 1 \mathrm{mV}$ at around $\mathrm{pH}$ 8.5. This can be attributed to the generation of carboxylate groups along with the neutralization of amines. As a result, the functionalized nanochannels become anionic above the isoelectric point of $\mathrm{pH} 6.0$ and cationic below pH 6.0.

The $\mathrm{pH}$ dependent charge switchable property of nanochannels was explored to encapsulate and release of cationic dye molecule. For this purpose, a cationic dye - crystal violet $\left(\mathrm{CV}^{+}\right)$was chosen which maintain the cationic nature in the $\mathrm{pH}$ range of 3 to $8.5 .^{48,49}$ The dye uptake and release were quantitatively probed via UV-Vis spectroscopy (Scheme 1, Fig. S8†). To investigate the amount of $\mathrm{CV}^{+}$encapsulation, $10 \mathrm{mg} \mathrm{MCM-Z}$ was soaked in a $3.34 \mu \mathrm{M}$ aqueous solution of $\mathrm{CV}^{+}$dye at $\mathrm{pH} 8$ for 10 minutes. The absorption spectra of $\mathrm{CV}^{+}$stock solution and supernatant solution after soaking with $\mathbf{M C M - Z}$ was compared (Fig. 2a). The disappearance of $\mathrm{CV}^{+}$absorption band for supernatant solution suggested an efficient encapsulation of cationic dye in negatively charged nanochannels at $\mathrm{pH} 8 \mathrm{via}$ electrostatic attraction. The encapsulation is driven by electrostatic attraction between the $\mathrm{CV}^{+}$and silica surface. There are no physically entrapped dye molecules inside the pore as it is evident from 'zero' leak release of $\mathrm{CV}^{+}$from silica pores at $\mathrm{pH}>$

(a)
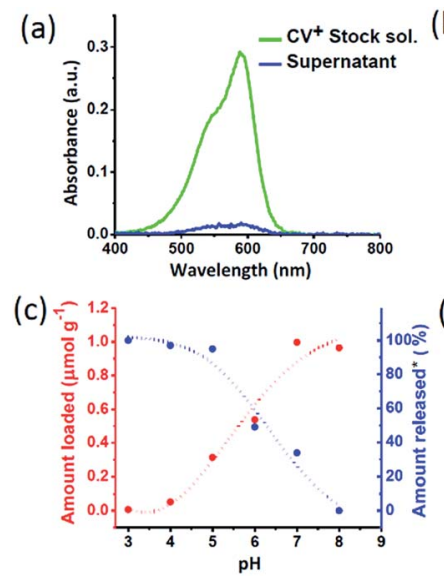

Fig. 2 Transportation of $\mathrm{CV}^{+}$in MCM-Z nanochannels: (a) absorption spectra of $\mathrm{CV}^{+}$stock solution and the supernatant after incubating with $\mathrm{MCM}-\mathrm{Z}$ at pH 8. (b) Amount of encapsulation of $\mathrm{CV}^{+}$into $\mathrm{MCM}-\mathrm{Z}$ at $\mathrm{pH} 3$ and $\mathrm{pH} 8\left(\mathrm{CV}^{+}\right.$stock solution concentration was $\mathrm{ca} .3 .34 \mu \mathrm{M}$ and $M C M-Z$ was $c a .10 \mathrm{mg}$ ). Photographs showing the supernatant solution after soaking $\mathrm{CV}^{+}$with $\mathrm{MCM}-\mathrm{Z}$ for $10 \mathrm{~min}$ in (i) $\mathrm{pH} 3$ and (ii) $\mathrm{pH}$ 8. (c) Encapsulation and release of $\mathrm{CV}^{+}$in $\mathrm{MCM}-\mathrm{Z}$ at different $\mathrm{pH}$. *For release studies, $\mathrm{CV}^{+}$was first encapsulated in to $\mathrm{MCM}-\mathrm{Z}$ at $\mathrm{pH} 8$ and the released amount at different $\mathrm{pH}$ was normalized w.r.t. loading at $\mathrm{pH}$ 8. (d) Cycling of $\mathrm{CV}^{+}$encapsulation into $\mathrm{MCM}-\mathrm{Z}$ at $\mathrm{pH} 3$ and 8 (see $\mathrm{ESI} \uparrow$ for the details).
8.0 (Fig. 2c). The uptake of $\mathrm{CV}^{+}$calculated from the UV-vis spectra was found to be ca. $1 \mu \mathrm{mol} \mathrm{g} \mathrm{g}^{-1}$ (Fig. 2b). Similar encapsulation experiment was done at $\mathrm{pH} 3$ and only a negligible uptake was observed, confirming the strong electrostatic gating of MCM-Z nanochannels at $\mathrm{pH} 3$ towards the cationic dye (Fig. 2b).

Next we studied the $\mathrm{CV}^{+}$dye uptake in $\mathbf{M C M}-\mathbf{Z}$ and its release as a function of $\mathrm{pH}$ (Fig. 2c). The MCM-Z (10 mg) was incubated in a $3.34 \mu \mathrm{M} \mathrm{CV}^{+}$solution at different $\mathrm{pHs}$ (in the range of 3-8) for 10 minutes and the encapsulation was probed with absorption spectra. A gradual increase in the uptake of $\mathrm{CV}^{+}$ was observed with increasing $\mathrm{pH}$ and a maximum uptake was seen at pH 8 ( ca. $\left.1 \mu \mathrm{mol} \mathrm{g}^{-1}\right)$ which can be explained based on the nature of surface charge developed at different $\mathrm{pH}$ as shown in Fig. 1b. Release profile of $\mathrm{CV}^{+}$encapsulated in MCM$\mathbf{Z}$ at $\mathrm{pH}$ 8.0 (high uptake due to electrostatic interactions) showed maximum release at $\mathrm{pH} 3.0$ due to the charge repulsion between the positively charged nanochannels and the cationic dye (Fig. 2c). We further investigated the recyclability of the charge reversal and dye encapsulation by sequentially changing the $\mathrm{pH}$ of the $\mathbf{M C M}-\mathbf{Z}$ dispersion containing $1 \mu \mathrm{mol}$ $\mathrm{g}^{-1} \mathrm{CV}^{+}$between 3 and 8 . The encapsulation and release of $\mathrm{CV}^{+}$ in and out of MCM-Z was studied and a significant amount of dye uptake was observed up to three cycles (>80\%) (Fig. 2d). Thus, we obtained an efficient recycling, validating the adaptability and reversibility of these nanochannels to solution $\mathrm{pH}$ variations.

Further, we investigated the structural stability of $\mathbf{M C M}-\mathbf{Z}$ in basic aqueous solution $(\mathrm{pH}>8.0)$ to evaluate the robustness of the nanochannels. The $\mathbf{M C M - Z}$ was dispersed in Tris buffer of pH $9.0(10 \mathrm{mM})$ and the zeta potential was measured at regular time intervals up to 3 hours, which showed no change even after 2.5 hours (Fig. S9a $\dagger$ ). The XRD pattern (Fig. S9b $\dagger$ ) and $\mathrm{N}_{2}$ sorption analysis (Fig. S9c $\dagger$ ) also confirmed the structural stability of MCM-Z nanochannels in basic conditions.

With the understanding of switchable charged nanochannels of MCM-Z at varying $\mathrm{pH}$ between 3 to 8 and corresponding cationic dye encapsulation and release, we next envisioned to couple this to a temporal change in $\mathrm{pH}$ to realize "transient ion transport". For this, we have exploited a feedback-controlled chemical processes which temporally modulates the $\mathrm{pH}$ of the surrounding solution. ${ }^{50}$ When we first inject a base to the acidic dispersion of $\mathbf{M C M}-\mathbf{Z}$, the increase in $\mathrm{pH}$ ( 9.0) deprotonates the carboxylic acid functional groups (and ammonium cations) resulting in the formation of anionic nanochannels (activation). Furthermore, the high $\mathrm{pH}$ initiates hydrolysis of ethyl acetate (by esterase enzyme) that gradually decreases the $\mathrm{pH}$ (due to the formation of acetic acid). As a result amine and carboxylate functional groups get protonated and nanochannels become cationic (deactivation). Since ethyl acetate decreases the $\mathrm{pH}$ of the system only via its kinetically controlled hydrolysis (by esterase enzyme) it is referred as dormant deactivator. The instantaneous activation (formation of anionic nanochannels) by the addition of base and the slow deactivation (leading to cationic nanochannels) due to ethyl acetate hydrolysis allow the nanochannels to exist in transient anionic state (Fig. 3a(i)). 
(a)

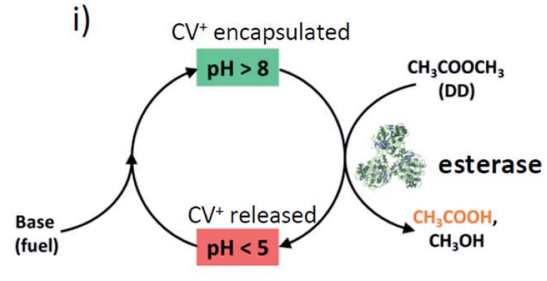

ii)

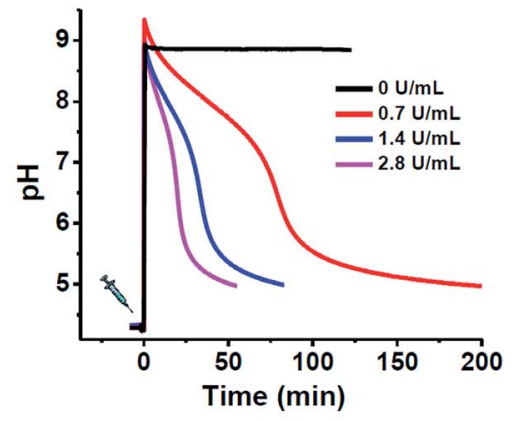

(b)

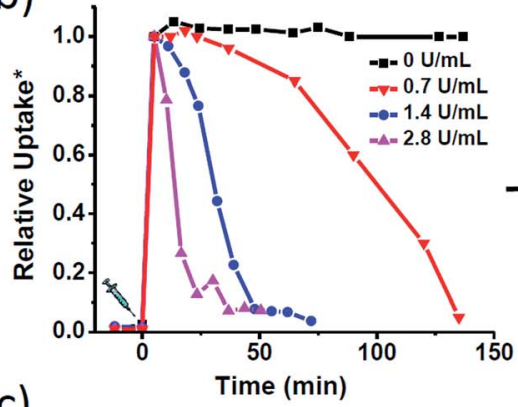

(c)

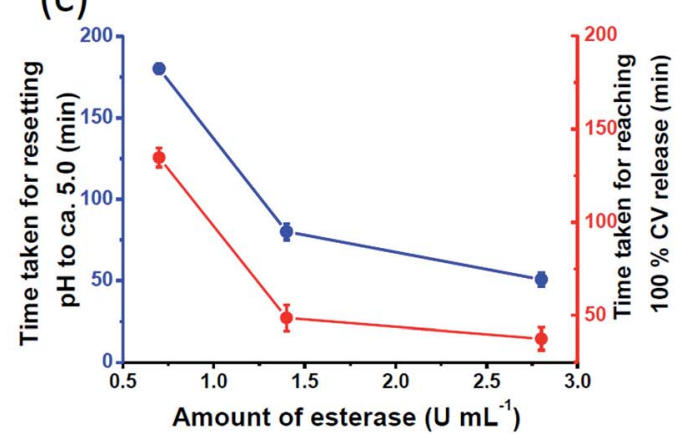

(d)

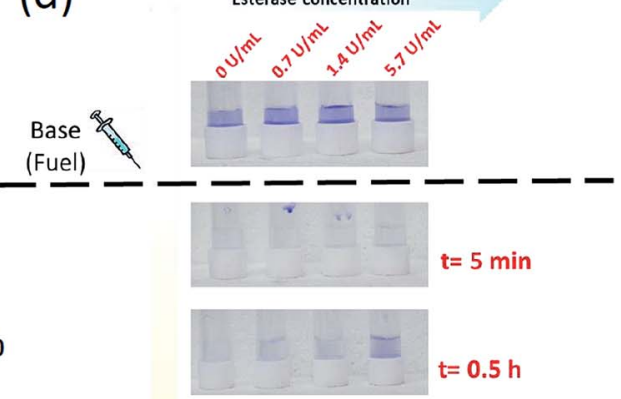

틀
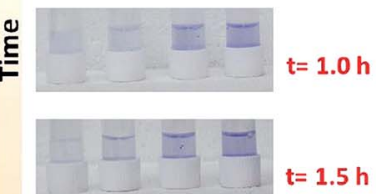

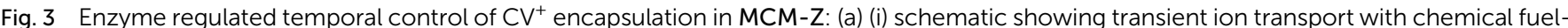

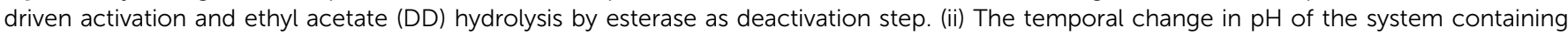

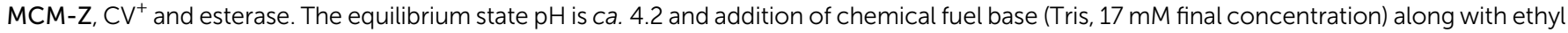

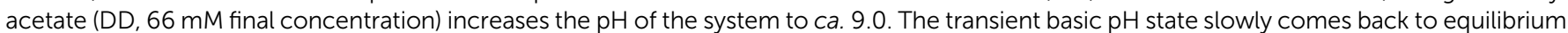

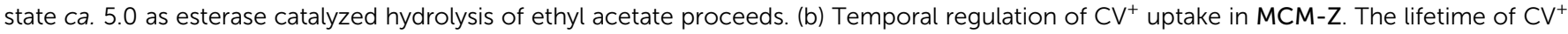

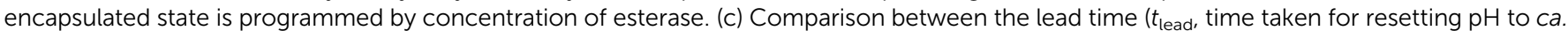

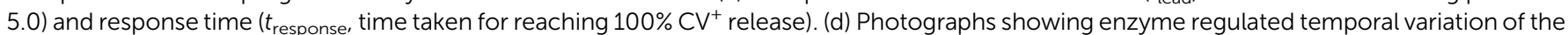
colour of supernatants. ${ }^{*}$ The $\mathrm{CV}^{+}$encapsulation is normalized w.r.t. amount of encapsulation at [esterase] $=0 \mathrm{U} \mathrm{mL}^{-1}$.

We first investigated the efficiency to obtain temporal control on $\mathrm{pH}$ by varying the amount of esterase. The chemical fuel (tris(hydroxymethyl)aminomethane (base)) and ethyl acetate (DD) in appropriate concentrations were mixed and injected to a dispersion of $\mathbf{M C M}-\mathbf{Z}$ containing $\sim 1.0 \mu \mathrm{mol} \mathrm{g}{ }^{-1}$ $\mathrm{CV}^{+}$and esterase enzyme $\left(0-3 \mathrm{U} \mathrm{mL}^{-1}\right)$ and a time dependent pH variation was monitored (Fig. 3a(ii)). An initial increase in $\mathrm{pH}$ to $\sim 9$ was observed that gradually decayed to equilibrium state acidic $\mathrm{pH} \sim 5.0$ due to the formation of acetic acid by the hydrolysis of ethyl acetate (DD). The kinetics of ethyl acetate hydrolysis is exclusively proportional to the concentration of esterase. The increase in concentration of enzyme (at constant concentration of ethyl acetate) resulted in higher rate of ethyl acetate hydrolysis and a corresponding decrease in lifetime of transient alkaline $\mathrm{pH}$ state. For ca. $0.7 \mathrm{U} \mathrm{mL}^{-1}$ of esterase enzyme, it took more than $180 \pm 3 \mathrm{~min}$ to return the $\mathrm{pH}$ back to ca. 5; however, it took only $50 \pm 4$ min when the enzyme amount was increased to $c a .2 .8 \mathrm{U} \mathrm{mL}^{-1}$ (Fig. 3c). On the other hand, the $\mathrm{pH}$ remained around 9.0 when no esterase was used attributing the importance of esterase enzyme to build transient profile. Interestingly, the temporal variation of solution $\mathrm{pH}$ showed three distinct slopes which were in agreement with the previously reported activity profile of esterase..$^{50}$

The temporal control achieved on $\mathrm{pH}$ was next coupled to $\mathrm{CV}^{+}$dye encapsulation in MCM-Z. Due to the above described in situ modulation of $\mathrm{pH}$, the permeation of ions in and out of the
pH adaptive MCM-Z nanochannels was expected to adjust autonomously (Fig. 2b, d). To achieve a temporal control on ion transport, MCM-Z, $\mathrm{CV}^{+}$and esterase enzyme at $\mathrm{pH} 4.2$ were taken. The system stays at equilibrium and insignificant encapsulation of $\mathrm{CV}^{+}$by $\mathbf{M C M}-\mathbf{Z}$ was observed even after $10 \mathrm{~min}$ of soaking (Fig. 3b). However, on addition of chemical fuel base (Tris) and ethyl acetate, resulted in an instantaneous increase in $\mathrm{pH}$ that facilitated a spontaneous $\mathrm{CV}^{+}$encapsulation in MCM-Z nanochannels. Subsequently, hydrolysis of ethyl acetate (DD) by esterase occurs that gradually decreased the $\mathrm{pH}$ and a slow $\mathrm{CV}^{+}$ release back into the solution is observed. Thus, a transient ion transport or transient molecule encapsulation is attained.

Further, the lifetime of the transient ' $\mathrm{CV}^{+}$encapsulated state' was programmed by modulating deactivation rate via enzyme concentration. In the case of $2.8 \mathrm{U} \mathrm{mL}^{-1}$ esterase concentration, within $38 \pm 6 \mathrm{~min}$ complete release was seen; on the other hand, when the esterase concentration was reduced to $0.7 \mathrm{U}$ $\mathrm{mL}^{-1}$, it took longer time to reach complete release $(>135 \pm 5$ min) (Fig. 3b-d). This clearly demonstrates the temporal programmability of $\mathrm{CV}^{+}$encapsulation and modular transient ion transport. Interestingly, we noted that for any esterase concentration, time taken for resetting $\mathrm{pH}$ back to the equilibrium $\mathrm{pH}$ (i.e. 5.0) ( $\left.t_{\text {lead }}\right)$ was higher than the time required for the complete release $\left(t_{\text {response }}\right)$ (Fig. $\left.3 \mathrm{c}\right)$.

The system was further scrutinized to test its ability to undergo multiple cycles on refuelling by chemical fuel (Tris) 


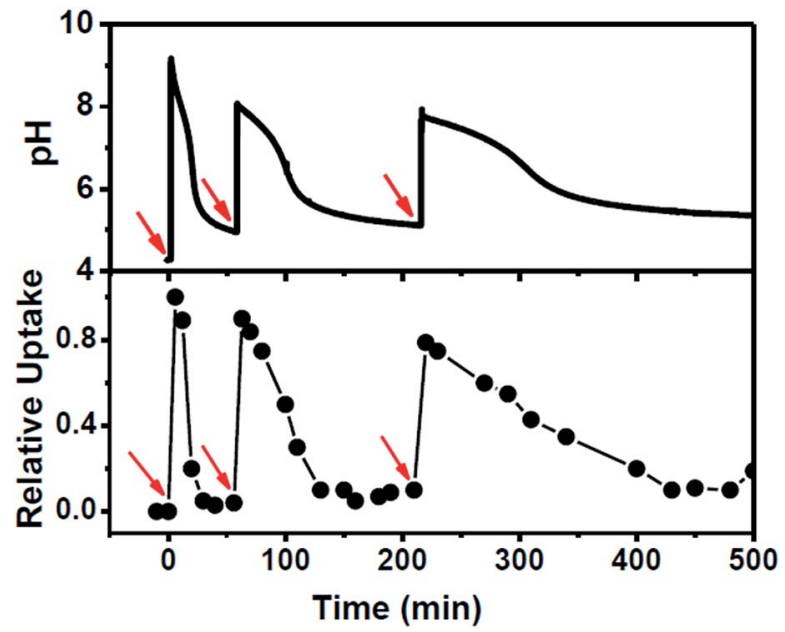

Fig. 4 Refuelling the system showing the recyclable nature of $\mathrm{CV}^{+}$ encapsulation and release in $\mathrm{MCM}-\mathrm{Z}$ along with corresponding $\mathrm{pH}$ trace. Red arrows indicate addition of fuel along with ethyl acetate (DD). Addition of base (fuel) increased $\mathrm{pH}$ of the dispersion and at basic $\mathrm{pH}$ ethyl acetate hydrolysis mediated by esterase decrease the $\mathrm{pH}$ gradually.

(Fig. 4). For this purpose, a dispersion containing $\mathbf{M C M}-\mathbf{Z}, \mathrm{CV}^{+}$ $\left(\sim 1.0 \mu \mathrm{mol} \mathrm{g}^{-1}\right)$ and $2.8 \mathrm{U} \mathrm{mL}^{-1}$ esterase was taken at a $\mathrm{pH}$ around 4.2 and the $\mathrm{pH}$ and $\mathrm{CV}^{+}$uptake was monitored (Fig. 4). As expected no uptake was observed at this equilibrium state. However, an instantaneous encapsulation of $\mathrm{CV}^{+}$was observed up on the addition of chemical fuel (Tris) (same amount used in the previous experiments). The $\mathrm{CV}^{+}$uptake was followed by gradual release as ethyl acetate (DD) hydrolysis proceeds (ethyl acetate was added along with chemical fuel). Once the system reached back to the equilibrium state, it was refuelled by adding same amount of chemical fuel (Tris) and ethyl acetate (DD) and a similar temporal profile was observed. Third refuelling also resulted in a similar trend. Thus system could be refuelled multiple times by subsequent addition of fuel, however, there was a dampening observed in the time required for complete release of $\mathrm{CV}^{+}$as the cycles proceeded. This can be attributed to the accumulation of waste products in the closed system. Nevertheless, we could obtain a transient ion transport and successfully modulate its temporal profile and refuel it multiple times.

\section{Conclusions}

In summary, we demonstrated the construction of mesoporous silica based biomimetic nanochannels having enzyme mediated autonomous (temporal) regulation over ion transport. The fuel driven encapsulation of ions into the nanochannels and temporal control of release have been shown for the first time in such nanochannels. A modular lifetime of transient ion transport was shown along with the refuelability of the system. The nanochannels were also found to be very robust in terms of structural stability in basic medium. These temporally switchable and adaptive nanochannels shall pave the way for future on demand devices or delivery vehicles.

\section{Conflicts of interest}

There are no conflicts to declare.

\section{Acknowledgements}

We thank Prof. C. N. R. Rao, F. R. S. for his support and encouragement. S. D. and S. J. G. thank Nanomission, DST (SR/ NM/TP-25/2016), JNCASR and Sheikh Saqr Laboratory (SSL) for financial support. S. J. G. gratefully acknowledges Swarna Jayanti Fellowship Award (DST/SJF/CSA-01/2016-2017). K. P. S. thanks B. V. V. S. Pavan Kumar for helpful discussions. M. E. thanks Sheikh Saqr Career Award Fellowship.

\section{Notes and references}

1 T. Mitchison and M. Kirschner, Nature, 1984, 312, 237.

2 E. D. Korn, Physiol. Rev., 1982, 62, 672-737.

3 R. Merindol and A. Walther, Chem. Soc. Rev., 2017, 46, 55885619.

4 S. A. P. van Rossum, M. Tena-Solsona, J. H. van Esch, R. Eelkema and J. Boekhoven, Chem. Soc. Rev., 2017, 46, 5519-5535.

5 L. Heinen and A. Walther, Soft Matter, 2015, 11, 7857-7866. 6 G. Ashkenasy, T. M. Hermans, S. Otto and A. F. Taylor, Chem. Soc. Rev., 2017, 46, 2543-2554.

7 J. Boekhoven, A. M. Brizard, K. N. K. Kowlgi, G. J. M. Koper, R. Eelkema and J. H. van Esch, Angew. Chem., Int. Ed., 2010, 49, 4825-4828.

8 J. Boekhoven, W. E. Hendriksen, G. J. M. Koper, R. Eelkema and J. H. van Esch, Science, 2015, 349, 1075-1079.

9 B. G. P. van Ravensteijn, W. E. Hendriksen, R. Eelkema, J. H. van Esch and W. K. Kegel, J. Am. Chem. Soc., 2017, 139, 9763-9766.

10 S. Dhiman, A. Jain, M. Kumar and S. J. George, J. Am. Chem. Soc., 2017, 139, 16568-16575.

11 S. Dhiman, A. Jain and S. J. George, Angew. Chem., Int. Ed., 2017, 56, 1329-1333.

12 K. Jalani, S. Dhiman, A. Jain and S. J. George, Chem. Sci., 2017, 8, 6030-6036.

13 J. P. Wojciechowski, A. D. Martin and P. Thordarson, J. Am. Chem. Soc., 2018, 140, 2869-2874.

14 B. Kemper, L. Zengerling, D. Spitzer, R. Otter, T. Bauer and P. Besenius, J. Am. Chem. Soc., 2018, 140, 534-537.

15 B. Dong, L. Liu and C. Hu, Biomacromolecules, 2018, 19, 3659-3668.

16 L. S. Kariyawasam and C. S. Hartley, J. Am. Chem. Soc., 2017, 139, 11949-11955.

17 C. G. Pappas, I. R. Sasselli and R. V. Ulijn, Angew. Chem., Int. Ed., 2015, 54, 8119-8123.

18 J. K. Sahoo, C. G. Pappas, I. R. Sasselli, Y. M. Abul-Haija and R. V. Ulijn, Angew. Chem., Int. Ed., 2017, 56, 6828-6832.

19 H. Che, S. Cao and J. C. M. van Hest, J. Am. Chem. Soc., 2018, 140, 5356-5359.

20 P. Rangadurai, M. R. Molla, P. Prasad, M. Caissy and S. Thayumanavan, J. Am. Chem. Soc., 2016, 138, 7508-7511. 
21 E. Del Grosso, A. Amodio, G. Ragazzon, L. J. Prins and F. Ricci, Angew. Chem., Int. Ed., 2018, 57, 10489-10493.

22 H. Che, B. C. Buddingh' and J. C. M. van Hest, Angew. Chem., Int. Ed., 2017, 56, 12581-12585.

23 C. Pezzato and L. J. Prins, Nat. Commun., 2015, 6, 7790.

24 S. Maiti, I. Fortunati, C. Ferrante, P. Scrimin and L. J. Prins, Nat. Chem., 2016, 8, 725-731.

25 F. della Sala, S. Maiti, A. Bonanni, P. Scrimin and L. J. Prins, Angew. Chem., Int. Ed., 2018, 57, 1611-1615.

26 T. Heuser, R. Merindol, S. Loescher, A. Klaus and A. Walther, Adv. Mater., 2017, 29, 1606842.

27 M. Kumar, N. L. Ing, V. Narang, N. K. Wijerathne, A. I. Hochbaum and R. V. Ulijn, Nat. Chem., 2018, 10, 696703.

28 B. Hille, Ion Channels of Excitable Membranes, Sinauer Associates, Inc., U.S.A., 2001.

29 W. Guo, Y. Tian and L. Jiang, Acc. Chem. Res., 2013, 46, 28342846.

30 B. Yameen, M. Ali, R. Neumann, W. Ensinger, W. Knoll and O. Azzaroni, J. Am. Chem. Soc., 2009, 131, 2070-2071.

31 X. Hou, F. Yang, L. Li, Y. Song, L. Jiang and D. Zhu, J. Am. Chem. Soc., 2010, 132, 11736-11742.

32 A. Brunsen, C. Díaz, L. I. Pietrasanta, B. Yameen, M. Ceolín, G. J. A. A. Soler-Illia and O. Azzaroni, Langmuir, 2012, 28, 3583-3592.

33 Q. Liu, K. Xiao, L. Wen, Y. Dong, G. Xie, Z. Zhang, Z. Bo and L. Jiang, ACS Nano, 2014, 8, 12292-12299.

34 A. D. Dinsmore, M. F. Hsu, M. G. Nikolaides, M. Marquez, A. R. Bausch and D. A. Weitz, Science, 2002, 298, 1006-1009. 35 A. J. Dzieciol and S. Mann, Chem. Soc. Rev., 2012, 41, 79-85. 36 J. Gao, B. Zhao, M. Wang, M. A. C. Serrano, J. Zhuang, M. Ray, V. M. Rotello, R. W. Vachet and S. Thayumanavan, J. Am. Chem. Soc., 2018, 140, 2421-2425.
37 I. R. Fernando, D. P. Ferris, M. Frasconi, D. Malin, E. Strekalova, M. D. Yilmaz, M. W. Ambrogio, M. M. Algaradah, M. P. Hong, X. Chen, M. S. Nassar, Y. Y. Botros, V. L. Cryns and J. F. Stoddart, Nanoscale, 2015, 7, 7178-7183.

38 R. Liu, Y. Zhang, X. Zhao, A. Agarwal, L. J. Mueller and P. Feng, J. Am. Chem. Soc., 2010, 132, 1500-1501.

39 S. Wu, X. Huang and X. Du, Angew. Chem., Int. Ed., 2013, 52, 5580-5584.

40 X. Yao, X. Chen, C. He, L. Chen and X. Chen, J. Mater. Chem. $B, 2015,3,4707-4714$.

41 A. Popat, J. Liu, G. Q. Lu and S. Z. Qiao, J. Mater. Chem., 2012, 22, 11173-11178.

42 L. Yuan, Q. Tang, D. Yang, J. Z. Zhang, F. Zhang and J. Hu, J. Phys. Chem. C, 2011, 115, 9926-9932.

43 C.-H. Lee, S.-H. Cheng, I.-P. Huang, J. S. Souris, C.-S. Yang, C.-Y. Mou and L.-W. Lo, Angew. Chem., Int. Ed., 2010, 49, 8214-8219.

44 L. Xing, H. Zheng, Y. Cao and S. Che, Adv. Mater., 2012, 24, 6433-6437.

45 J.-T. Sun, C.-Y. Hong and C.-Y. Pan, J. Phys. Chem. C, 2010, 114, 12481-12486.

46 S. Huh, J. W. Wiench, J.-C. Yoo, M. Pruski and V. S. Y. Lin, Chem. Mater., 2003, 15, 4247-4256.

47 B. V. V. S. P. Kumar, K. Salikolimi and M. Eswaramoorthy, Langmuir, 2014, 30, 4540-4544.

48 J. D. Fisk, R. Batten, G. Jones, J. P. O'Reill and A. M. Shaw, J. Phys. Chem. B, 2005, 109, 14475-14480.

49 V. Manzo, O. Navarro, L. Honda, K. Sánchez, M. Inés Toral and P. Richter, Talanta, 2013, 106, 305-308.

50 L. Heinen, T. Heuser, A. Steinschulte and A. Walther, Nano Lett., 2017, 17, 4989-4995. 